\title{
A global assessment of the gender gap in self-reported health with survey data from 59 countries
}

Ties Boerma* (D), Ahmad Reza Hosseinpoor, Emese Verdes and Somnath Chatterji

\begin{abstract}
Background: While surveys in high-income countries show that women generally have poorer self-reported health than men, much less is known about gender differences in other regions of the world. Such data can be used to examine the determinants of sex differences.

Methods: We analysed data on respondents 18 years and over from the World Health Surveys 2002-04 in 59 countries, which included multiple measures of self-reported health, eight domains of functioning and presumptive diagnoses of chronic conditions. The age-standardized female excess fraction was computed for all indicators and analysed for five regional groups of countries. Multivariate regression models were used to examine the association between country gaps in self-reported health between the sexes with societal and other background characteristics.

Results: Women reported significantly poorer health than men on all self-reported health indicators. The excess fraction was $15 \%$ for the health score based on the eight domains, $28 \%$ for "poor" or "very poor" self-rated health on the single question, and $26 \%$ for "severe" or "extreme" on a single question on limitations. The excess female reporting of poorer health occurred at all ages, but was smaller at ages 60 and over. The female excess was observed in all regions, and was smallest in the European high-income countries. Women more frequently reported problems in specific health domains, with the excess fraction ranging from $25 \%$ for vision to $35 \%$ for mobility, pain and sleep, and with considerable variation between regions. Angina, arthritis and depression had female excess fractions of 33,32 and $42 \%$ respectively. Higher female prevalence of the presumptive diagnoses was observed in all regional country groups. The main factors affecting the size of the gender gap in self-reported health were the female-male gaps in the prevalence of chronic conditions, especially arthritis and depression and gender characteristics of the society.
\end{abstract}

Conclusions: Large female-male differences in self-reported health and functioning, equivalent to a decade of growing older, consistently occurred in all regions of the world, irrespective of differences in mortality levels or societal factors. The multi-country study suggests that a mix of biological factors and societal gender inequalities are major contributing factors to gender gap in self-reported measures of health.

Keywords: Self-reported health, Gender differences, Health surveys, Behavioural factors, Biological factors, Gender inequality, Chronic conditions

\footnotetext{
* Correspondence: boermat@who.int

Department of Information, Evidence and Research, World Health

Organization, Geneva, Switzerland
} 


\section{Background}

Globally, women have an average life expectancy that is about 5 years longer than that men, as a result of lower mortality rates at all ages [1]. There is, however, also evidence from household surveys in mostly high-income countries indicating that women consistently report a poorer health status than men [2, 3]. As a result the gap between the sexes is smaller for measures that combine mortality and morbidity, such as healthy life expectancy (4 years at birth), than for life expectancy (5 years at birth) [4].

The existence of sex differences in mortality and morbidity has stimulated research into the extent to which gender roles are playing a role. The proposed explanations for the health-survival paradox are rooted in biological, social and psychological interpretations [5]. In this study the focus is on the gap in self-reported health of women and men, which has been attributed to a range of a combination of biological, socio- behavioural and psychological differences which may result in reporting differences [3]. Studies in mostly high-income countries suggest that physical health status differences as well as mental health issues are important underlying factors [3, 6-8]. Differences in sociobehavioural factors such as employment and educational differences between men and women have also shown to be associated with gender differences in self-reported health $[9,10]$, as well as risk behaviour patterns such as smoking [3]. Some have suggested that a reporting bias, associated with gender-associated psychosocial factors or with actual use of healthcare, contributes to a greater propensity to report poor health in surveys among women [11-13].

A global study of the existence and size of a gap in self-reported health between the sexes allows an assessment of the consistency of the patterns in widely divergent sociocultural and economic settings and provides insight into the extent to which societal characteristics may influence the size of the gaps. This study examines the gap with data on multiple indicators of self-reported health among respondents 18 years and over from 59 countries, using the World Health Survey 2002-2004. The World Health Survey included a range of questions on domains of self-reported health and symptoms of chronic conditions. An ecological analysis is conducted to assess which societal determinants may affect the selfreported health gap in in this group of highly variable socio-economic and cultural settings. This includes an assessment of the association with male-female differences in employment and education, as well as gender inequality.

\section{Methods}

The World Health Survey (WHS) was conducted between 2002 and 2004 in 70 countries in all regions of the world and coordinated by the World Health Organization. The primary aim was to provide representative and comparable population data on the health status of adults 18 years and older. All countries conducted nationally representative surveys but in six the sample did not cover the whole country (China, Comoros, Congo, Cote d'Ivoire, India and Russia). The mean sample size was over 4000 respondents, ranging from about 1000 to over 20,000. Eleven countries were excluded from this analysis because of lack of data on sampling weights. The 59 countries included 143,363 male and 115,321 female respondents for the analysis. (For more details on the WHS, see www.who.int/healthinfo/survey/ en/).

The surveys were classified into six country groups including sub-Saharan Africa (17 countries), high income countries in Europe (nine countries), middle income countries in Eastern Europe (nine countries), Latin America (six countries) and South Asia (six countries); the remaining 12 countries were categorised as other to allow concise presentation of the results. (see Additional file 1 for details). All regional and global statistics are weighted using post-sample stratification weights.

Three self-reported measures of health were used [14-16]. First, a health (state) score derived from 16 questions in eight health domains: mobility, vision, cognition, self-care, personal interrelationships, sleep, affect and pain. The full questionnaire module is provided in Additional file 2. The Rasch partial credit model of Item Response theory was used to construct a composite score [17]. The inverse of the score obtained from the model was transformed to a scale ranging from 0 (best) to 100 (worst) called the "poor-health" score in this paper.

The second measure was based on a single question of overall self-rated health: "How would you rate your health today?", with responses on a five point Likert scale. The responses "bad" and "very bad" were considered to indicate poor self-rated health $[18,19]$. Finally, respondents in 51 surveys were asked: "Overall in the last 30 days, how much difficulty did you have with work or household activities Respondents were considered to have significant limitations in day to day activities if the response was "severe" or "extreme". Similar questions are included in widely used general population survey measures such as the EQ-5D-5 L and comparisons show that the two severe and extreme categories are equivalent to significant difficulties when only the three level version is used [20, 21].

In addition, symptom questions were asked to assess the prevalence of probable chronic conditions, based on recall of doctor's diagnosis plus symptom questions among those with no recall of diagnosis. This included angina pectoris, based on the algorithm based on the Rose questionnaire [22, 23], asthma and arthritis, both 
based on algorithms derived from questionnaires used previously in general populations studies [24-26], and depression based on questions based on the depression module of the World Mental Health Survey version of the Composite International Diagnostic Interview [27]. For diabetes, self-reported diagnosis was used, as no satisfactory diagnostic algorithm based on symptoms is currently available.

The size and distribution of the gender gap by region was examined for the three measures of self-reported health, the eight domains health separately, and the survey-based diagnoses of chronic conditions using the (female) excess fraction (defined as female prevalence minus male prevalence, divided by female prevalence) [28].

In addition, the association between the gap in women and men's self-rated health and selected socioeconomic, demographic and socio-behavioural factors was examined using aggregate country data on the following variables:

- Life expectancy gap (in years): based on WHO data for 2000 [1]). Mortality levels may have an association with the size of the gaps in self-reported health;

- Islamic countries: Islam is the majority religion (13 countries, see Additional file 1). Religion may be considered a proxy for societal and behavioural differences between men and women that affect self-reported health;

- Total Fertility Rate: number of children born to a woman at the end of her reproductive years, for the year 2000 [1]. Childbearing may have an impact on women's health;

- Employment gap: difference in the proportion of men and women who reported themselves in formal employment in the WHS. Studies have shown the association between employment and health [9];

- Education gap: difference in mean number of years of education between men and women in the WHS. Education has a strong relationship with health in many settings;

- Gross Domestic Product (GDP) per capita: in international dollars, PPP adjusted, for the year 2000 [1];

- Gender inequality index: a composite measure produced by the United Nations Development Programme based on reproductive health (maternal mortality and adolescent birth rate), empowerment (based on secondary education levels among women compared to men and female occupation of parliamentary seats) and female labour force participation [29];

- Smoking gap: difference between male and female current daily smoking rates, data from the WHS 2002-04;
- Alcohol use gap: difference between male and female prevalence in current use of alcohol, data from the WHS 2002-04.

In all analyses age-standardized rates were used. Multivariate regression models with country aggregate data were used to examine the association between gender gaps in each of the three measures of health with demographic, socio-behavioural and biological factors. Because of collinearity between the different variables, we opted for a stepwise regression with a cut-off of $10 \%$ to obtain insights into factors affecting the size of the gender gap. For the analysis of activity limitations we excluded Slovakia as it was a major outlier in the size of the gender gap affecting the results (a difference of 7 percentage points with women being worse as compared to the average pooled difference of about 3 percentage points). All analyses were weighted and conducted in Stata version 11.

Informed consent was obtained in all surveys. A standard consent form approved by the ethics review committee was read to the respondent in the respondent's language. If the respondent was literate and gave consent to participate, the form was provided to the respondent to read and sign, and was countersigned by the interviewer. If the respondent was illiterate and gave consent to participate, the interviewer confirmed this consent by signing that the respondent had been read the form, understood the study, and agreed to participate. This procedure was approved by the institutional review boards in each study country. The anonymised datasets are in the public domain (http://apps.who.int/healthinfo/ systems/surveydata/index.php/catalog/central) and this study is based on secondary analysis of these datasets and hence no additional ethical clearance was sought.

\section{Results}

\section{Overall health}

Table 1 presents the three self-reported health measures by sex, age and regional groups. For both men and women the prevalence of poor health increased with age. In general, respondents in the high-income countries in Europe and Latin America had lower selfreported prevalence of health problems than other regions.

There was considerable variation between individual countries (see Additional file 3). Major outliers were Swaziland and Morocco which had much higher selfreported prevalence of health problems than all other countries. Association between the self-reported prevalence of poor health and life expectancy in countries was weak for all three measures and for both sexes (Pearson correlation coefficients ranging from -.16 to -.27). The three measures were closely correlated with each other. 
Table 1 Self-reported health among men and women and female excess fraction, by age and country grouping: domain-based poor-health score, poor self-rated health and limitations in daily activities, WHS 2002-2004

\begin{tabular}{|c|c|c|c|c|c|c|c|c|c|}
\hline & \multicolumn{3}{|c|}{ Poor health score } & \multicolumn{3}{|c|}{ Poor self-rated health } & \multicolumn{3}{|c|}{ Limitations in daily activities } \\
\hline & Women (\%) & Men (\%) & $\overline{\text { Excess }(\%)^{a}}$ & Women (\%) & Men (\%) & $\overline{\text { Excess }(\%)^{\mathrm{a}}}$ & Women (\%) & Men (\%) & Excess $(\%)^{2}$ \\
\hline \multicolumn{10}{|l|}{ Age (years) } \\
\hline $18-29$ & 22.0 & 18.5 & 16 & 4.4 & 3.3 & 26 & 3.8 & 3.1 & 19 \\
\hline $30-39$ & 24.6 & 20.4 & 17 & 7.1 & 5.0 & 30 & 6.2 & 4.8 & 23 \\
\hline $40-49$ & 27.9 & 23.5 & 16 & 10.7 & 6.8 & 36 & 9.6 & 6.1 & 37 \\
\hline $50-59$ & 31.6 & 26.7 & 15 & 15.9 & 10.9 & 31 & 12.3 & 9.3 & 24 \\
\hline $60-69$ & 34.6 & 30.4 & 12 & 21.1 & 17.0 & 19 & 18.4 & 14.3 & 22 \\
\hline 70-79 & 38.6 & 34.9 & 9 & 30.6 & 22.8 & 26 & 30.1 & 21.5 & 28 \\
\hline $80+$ & 42.2 & 38.6 & 9 & 34.2 & 26.9 & 21 & 43.0 & 35.1 & 18 \\
\hline \multicolumn{10}{|l|}{ Region } \\
\hline Sub-Saharan Africa & 28.8 & 24.9 & 14 & 13.8 & 10.1 & 27 & 11.3 & 9.5 & 16 \\
\hline Latin America & 27.8 & 22.7 & 18 & 7.9 & 5.1 & 35 & 7.0 & 5.0 & 29 \\
\hline Europe, high-income & 24.6 & 21.6 & 12 & 8.5 & 6.7 & 21 & - & - & - \\
\hline Eastern Europe & 27.4 & 23.3 & 15 & 13.8 & 11.1 & 20 & 9.9 & 7.3 & 26 \\
\hline South Asia & 27.2 & 22.9 & 16 & 10.1 & 6.6 & 35 & 9.8 & 6.7 & 32 \\
\hline Other & 29.4 & 24.5 & .17 & 12.4 & 8.0 & 35 & 13.4 & 8.1 & 40 \\
\hline Total & 27.6 & 23.5 & 15 & 11.5 & 8.3 & 28 & 10.3 & 7.7 & 26 \\
\hline
\end{tabular}

${ }^{a}$ Excess is the female excess fraction; for domain health score the inverse was used; All female-male differences are statistically significant at the $1 \%$ level, as sample sizes of the pooled data sets are very large; All regional figures are age-standardized. -: only two countries in the region included the question

Among women, the correlation coefficients for the country aggregate scores were $.83, .75$, and .60 between self-reported health and activity limitations, activity limitations and poor health score, and self-reported health and poor health score respectively. The corresponding coefficients for men were somewhat lower than for women $(.77, .64$ and .44 respectively).

Women reported poorer health than men on all three measures. For the full data set, the excess fraction was $15 \%$ for the health score based on the eight domains, $28 \%$ for "poor" or "very poor" self-rated health on the single question, and $26 \%$ for "severe" or "extreme" on the single question on limitations. The excess female reporting of poorer health occurs at all ages, but is smaller at ages 60 and over than below 60 years for all three measures. The gap in health score declines gradually with age and was smallest at 80 years and over. The gender gap based on the single self-rated health and on the activity limitations indicators peaked at ages 4049 years.

The European country groups and sub-Saharan Africa had the smallest gender differences (Table 1). The largest female excess fractions were observed for the countries in the Latin America and South Asia regions as well as in the group "Other".

The differences in the domain-based health score are observed in all 59 country surveys with the exception of Norway where women had a higher score than men.
Women also reported poorer health on the single selfrated health question for 52 of 59 country surveys, with the exception of seven European countries (Estonia, Finland, Hungary, Latvia, Norway and Ireland), and for 46 of 51 countries on the limitations in daily activities question (the exceptions were Hungary, Latvia, Comoros, Ghana and Namibia). Figure 1 shows the pooled results of the differences between men and women in the health score across ages. Women are consistently in worse health than men across all age groups. This difference in the score is of about a decade of ageing - in other words a woman in a younger age group has the same level of health as a man in the next decade of age.

\section{Domain differences}

The upper panel of Table 2 shows the relative female excess of "severe" or "extreme" reporting for each of the eight domains of the health score, each based on two questions. (We also examined excess reporting for the 16 individual questions of the self-reported health score. The emerging gender patterns were similar to those presented here.) The large differences between women and men occurred in all regions and for all eight domains. Overall, the remarkably small range of the excess fraction was $25 \%$ for vision to $35 \%$ for mobility, pain and sleep.

Regional patterns varied. In the high-income country group there was most variability, with large female 


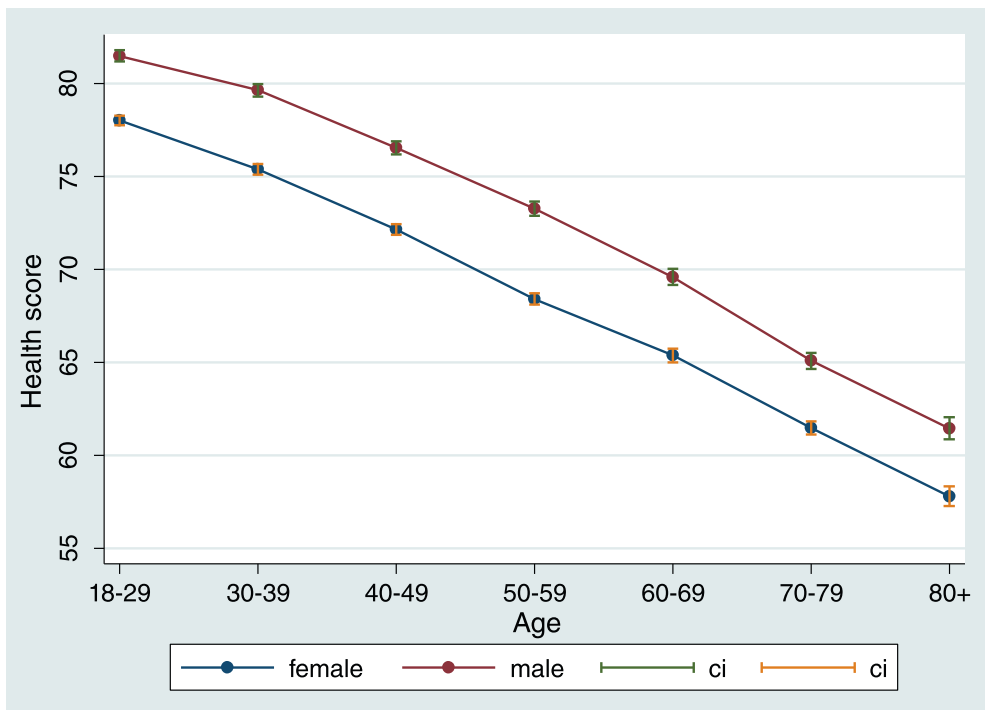

Fig. 1 Levels of health pooled across the 59 surveys for men and women by age - mean levels and standard errors

excess for the domains of affect, sleep and vision and small for personal care, cognition and self-care. Other regions generally had much smaller variation in the gender gap by domain.

\section{Chronic conditions}

The lower panel of Table 2 shows the excess fraction of a presumptive diagnosis by region. Angina, arthritis and depression had female excess fractions of 33, 32 and $42 \%$ respectively, occurring in all regional groups.
Depression had the largest excess fractions, especially in the European country groups and Latin America. For asthmatic conditions and diabetes the gender gaps were small overall and consistently so in all regions.

\section{Other differences}

Overall, $19.9 \%$ of women and $16.7 \%$ of men were not satisfied with their own health, an excess fraction of $16 \%$. (detail in Additional file 4) The proportion rose

Table 2 Excess fraction women over men by health domains and algorithm-based diagnoses, by region, World Health Survey $2002-04$

\begin{tabular}{|c|c|c|c|c|c|c|c|c|c|}
\hline & \multicolumn{2}{|c|}{ Prevalence (\%) } & \multirow[b]{2}{*}{ Total } & \multirow[b]{2}{*}{ Sub-Saharan Africa } & \multirow[b]{2}{*}{ Latin America } & \multicolumn{2}{|l|}{ Excess (\%) ${ }^{a}$} & \multirow[b]{2}{*}{ South Asia } & \multirow[b]{2}{*}{ Other } \\
\hline & Women & Men & & & & Europe, high income & Eastern Europe & & \\
\hline \multicolumn{10}{|l|}{ Domains } \\
\hline Mobility & 23.7 & 15.4 & 35 & 35 & 44 & 19 & 26 & 35 & 41 \\
\hline Self-care & 3.9 & 2.7 & 31 & 24 & 12 & 17 & 30 & 30 & 53 \\
\hline Pain & 14.6 & 9.5 & 35 & 27 & 43 & 35 & 31 & 41 & 45 \\
\hline Cognition & 10.5 & 7.0 & 33 & 27 & 45 & 14 & 22 & 36 & 46 \\
\hline Relationships & 5.5 & 3.9 & 28 & 20 & 36 & 2 & 27 & 32 & 41 \\
\hline Vision & 8.6 & 6.4 & 25 & 19 & 27 & 49 & 28 & 23 & 41 \\
\hline Sleep & 12.5 & 8.1 & 35 & 26 & 46 & 49 & 31 & 41 & 39 \\
\hline Affect & 15.2 & 11.1 & 27 & 26 & 43 & 59 & 43 & 13 & 19 \\
\hline \multicolumn{10}{|c|}{ Diseases based on algorithms } \\
\hline Angina & 12.9 & 8.7 & 33 & 36 & 42 & 15 & 37 & 26 & 33 \\
\hline Arthritis & 9.2 & 6.3 & 32 & 21 & 42 & 24 & 35 & 33 & 36 \\
\hline Asthma & 7.4 & 6.8 & 8 & 18 & 25 & 0 & 1 & 1 & 0 \\
\hline Depression & 8.2 & 4.8 & 42 & 32 & 54 & 55 & 55 & 34 & 39 \\
\hline Diabetes $^{a}$ & 3.8 & 3.3 & 14 & 16 & 30 & -12 & 10 & 1 & 21 \\
\hline
\end{tabular}

${ }^{a}$ Excess is the female excess fraction; for domains of health a score combining the two questions in each domain (see Additional file 1) was used; all female-male differences are statistically significant at the $1 \%$ level; all figures are weighted and age-standardized 
with age for both sexes until ages 50-59, but the sex differences remained fairly constant from age 60 .

Women were more frequent users of ambulant health services, but the differences were modest: 50 and $43 \%$ of women and men respectively made at least one visit for ambulant health care in the last 12 months. Women had also been admitted more frequently to a hospital in the last 5 years: 25 and $17 \%$ for women and men respectively. The greater use of inpatient services by women however was limited to ages 18-39 years, and presumably associated with the female reproductive ages, as the gender gap was negligible for ages 40 and over (see Additional file 4).

\section{Factors affecting the gender gap}

Table 3 presents the results of the analysis of factors influencing the size of the country gender gaps for each of the three measures of self-reported health. The table only includes variables that were significantly associated with self-reported health measures at the $10 \%$ level in a bivariate regression. No association was observed for many variables, including gender gaps in life expectancy, smoking and alcohol use. Region was not a significant factor with the exception of a smaller gap in self-rated

Table 3 Association between the gender gap in three self-reported health measures and determinants, World Health Survey 59 countries (coefficients with $p$-value of $t$-test shown)

\begin{tabular}{lll}
\hline & Bivariate & Multivariate \\
\hline A Domain poor-health score & & \\
Employment gap & $.0010(.090)$ & $.0174(.012)$ \\
Education gap & $.0132(.100)$ & $\mathrm{a}$ \\
Life expectancy gap & $-.0066(0.09)$ & $\mathrm{a}$ \\
Depression gap & $.0128(<.001)$ & $.0115(<.001)$ \\
Arthritis gap & $.0115(.006)$ & $.0084(.033)$ \\
B Overall Self-rated health & & \\
Gender inequality index & $.0581(.020)$ & $\mathrm{a}$ \\
High income countries & $-.3350(.027)$ & $\mathrm{a}$ \\
Islamic country & $.1823(.098)$ & $\mathrm{a}$ \\
Employment gap & $.0059(.007)$ & $.0058(.008)$ \\
Depression gap & $.0310(.026)$ & $\mathrm{a}$ \\
Arthritis gap & $.0604(.001)$ & $.0051(.008)$ \\
C Daily Activity limitations & & \\
Depression gap & $.0858(.003)$ & $\mathrm{a}$ \\
Arthritis gap & $.1180(.001)$ & $.0384(.015)$ \\
Angina gap & $.1010(.001)$ & $\mathrm{a}$ \\
Diabetes gap & $-.1575(.013)$ & $\mathrm{a}$ \\
\hline
\end{tabular}

Bivariate regression column only includes variables with an association significant at the $10 \%$ level; Multi-variate regression model only includes variables remaining significant at the $10 \%$ level in a stepwise regression; (a) means removed from model because $p>.10$; Model A: $r^{2}=0.37$; model B: $r^{2}=0.30$; model $\mathrm{C}: \mathrm{r}^{2}=0.12$ health in high-income countries compared to all other countries which disappeared in the multivariate analysis.

Greater gender inequality, as measured by the gender equality index and by gaps in employment and education were significant factors affecting the size of the females excess fraction in several models. The size of the gender gap was associated with the excess fraction for arthritis for all three measures of self-reported health. The depression prevalence gap between women and men was also associated with all three measures in bivariate analysis, but only in multivariate analysis only significantly so for the domain-based health score.

Figure 2 shows the female excess fraction in selfreported health if there was no chronic condition; any chronic condition; but no depression, and any chronic condition including depression. The gender gap was considerably smaller if women and men had the same chronic conditions, especially if depression was also diagnosed. The patterns were similar in all regions, except the two European country groups.

\section{Discussion}

The analysis of World Health Survey data from 59 countries shows a large and consistent gender gap in reporting of health problems in all regions. Women had much higher prevalence of poor health than men for each of three indicators of self-reported health, as well as eight functional domains. The overall consistency in the size of the gap among the eight domains was notable. In addition, women of all ages had higher prevalence of three algorithm-based diagnoses of depression, angina and arthritis. In general, regional patterns in the selfreported health gap between the sexes were also remarkably similar.

The size of the gender gap in self-reported health was influenced by both societal and biological factors. Gender gaps in employment and education, as well as greater gender inequality, were significant factors in some models. An individual-level analysis of selfreported health by gender of the World Health Survey also showed that some of the differences between women and men could be attributed to social determinants, mostly employment levels [8]. Behavioural factors such as smoking or alcohol differences between the sexes had no effect. Overall, the effects of gender inequality in societies, either measured through the gender inequality index, education or employment, appeared to be modest in terms of explaining why women report much poorer health than men. The level of fertility or mortality in a country did not explain the gender gap in self-reported health.

The consistency of the findings of across regions suggests that biological differences between women and men are a key factor contributing to the gender gaps in 


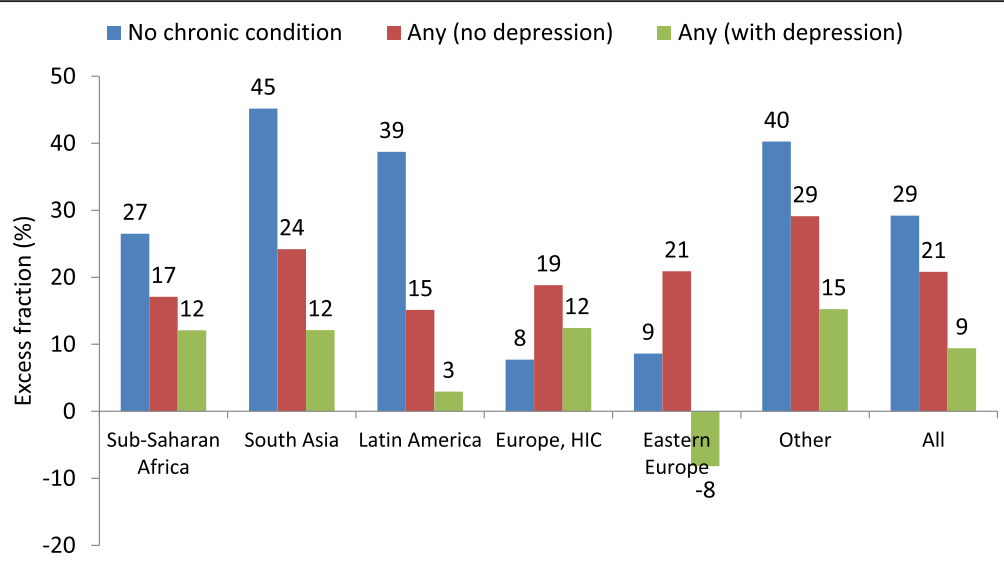

Fig. 2 Women excess fraction for three health measures by different combinations of presumptive diagnosis of chronic conditions

self-reported health. Our results from the composite domain health score show the dramatic difference between the levels of health between women and men - equivalent to a decade of ageing. The gender gap in self-reported health was associated with differences in the prevalence of chronic conditions, based on recall and symptom questions, notably arthritis and depression. Data from surveys in high-income countries have also suggested a substantive role of disease prevalence, as female-male differences were much smaller when the prevalence of self-reported chronic diseases and functioning were taken into account $[2,3]$. There was also a larger gender gap between ages 40-59 years, perhaps related to the menopause or greater male underreporting but the study could not provide any insights into possible causes for this age pattern.

The higher prevalence of conditions among women can be due to higher incidence or lower case fatality rates. Women at all ages reported more chronic conditions that are non-fatal but are debilitating such as arthritis, depression, cognitive loss, asthma, but men may have more cardiovascular diseases and maybe more likely to suffer from acute conditions with higher case fatality $[3,30]$. There was however no evidence of a survivor bias in the self-reported health, as the gender gaps did not increase with age. The opposite occurred in our analysis, which has also been observed in several studies in high-income countries [2,31].

Depression as measured in the World Health Surveys was common, especially among women, and has been linked with higher self-reported levels of health problems [7]. The presumptive diagnosis was based on the full syndromal criteria for depression as described in the International Classification of Diseases [32] which is distinct from occasional mood fluctuations and correlates with well biological mechanisms [33]. In addition, previous analyses have shown that the decrements in health associated with depression are not attributable to reporting biases or the domains used in our analyses [8].
Depression may be an underlying factor for the gender gaps in self-reported health that affects all indicators. It is noted that the domain-based health score itself includes several mental health related items such as cognition, sleep and interpersonal relationships, which implies that the results have to be interpreted with caution. However, earlier analysis of the World Health Surveys showed that this is unlikely due to a bias resulting from the inclusion of affect related items in the overall poorhealth score [7].

Health service utilization by women tends to be at least equal or higher than that for men in virtually all countries. Therefore, differential access and utilization of health services is not a likely reason for gender differences in the prevalence of health problems, unless the quality of treatment received differs greatly and in all societies. The more frequent contact with health services among women could contribute to the gender gap in reporting, due to higher awareness and reporting of recalled doctor's diagnoses and symptoms.

In addition to the limitations discussed above it is noted that the quality of the World Health Surveys data is likely to be variable, as the capacity of the implementing agencies is likely to have varied between countries. The individual response rates were not significantly different between males and females in any country [34]. In spite of possible quality differences in country surveys the consistency of the gender gap in self-reported health is remarkable and gives confidence in the conclusion about its generalizability. Also the World Health Surveys did not include biological or clinical data which may throw further light on the gender differences. The WHO longitudinal study on adult health and ageing (SAGE), implemented in six countries, does include biological and clinical data collection and will be used for further analyses of self-reported health and gender gaps [35].

Single questions on overall self-rated health are commonly used to compute a population health summary 
measure, such as healthy life expectancy [4]. A substantial large drawback of such single overall self-reported health measures is the large counterintuitive variation between populations and over time [36]. One way to address this problem is to include a composite measure of self-reported health derived from difficulties in functioning in multiple domains as was done in our 'poor-health' measure.

The analysis focused on the gap in health across countries with different social, economic and cultural contexts and hence we included the country as a dummy variable in our analyses in addition to the other variables that could be construed as 'ecological'. If health gap between the sexes is described as an individual level variable, multi-level modeling where individuals and country are treated as separate levels or include interaction terms between country and gender can be used to further disentangle gender differences in the different societal contexts. This could build upon a decomposition analysis that was conducted using the same data set to understand the determinants of health among men and women at the individual level [9].

\section{Conclusion}

The consistent widespread gap in self-reported health measures between men and women observed in this study of 59 countries across the globe is remarkable and the gap should be taken into account in all work in search of summary measures of population health that include self-reported data and to examine increasing divergence between life expectancy and healthy life expectancy as populations age worldwide. The multi-country study suggests that a combination of societal and biological factors is contributing to the large differences between in self-reported health by women and men in all regions of the world.

\section{Additional files}

Additional file 1: Country surveys. (DOCX $14 \mathrm{~kb}$ )

Additional file 2: Questionnaire. (DOCX $23 \mathrm{~kb}$ )

Additional file 3: Country data. (XLSX $20 \mathrm{~kb}$ )

Additional file 4: Service utilization. (XLSX $10 \mathrm{~kb}$ )

\section{Funding}

No specific funding was obtained for this study.

\section{Availability of data and materials}

The anonymised datasets are in the public domain http://apps.who.int/ healthinfo/systems/surveydata/index.php/catalog/central

The questionnaires and other materials can be found at: http://www.who.int/ healthinfo/survey/en/. All data used in this analyses are included as Additional files 1, 2, 3 and 4 .

\section{Authors' contribution}

TB, ARH and SC developed the design of this study. All four authors contributed to the analysis and write-up of the paper. EV wrote the statistical code. All authors read and approved the final version.

\section{Competing interests}

The authors declare that they have no competing interests.

\section{Consent for publication}

Not applicable.

\section{Ethics approval and consent to participate}

Informed consent was obtained in all World Health Surveys. A standard consent form approved by the ethics review committee was read to the respondent in the respondent's language. If the respondent was literate and gave consent to participate, the form was provided to the respondent to reasd and sign, and was countersigned by the interviewer. If the respondent was illiterate and gave consent to participate, the interviewer confirmed this consent by signing that the respondent had been read the form, understood the study, and agreed to participate. The surveys and this procedure was approved by the institutional review boards in each of the 70 study countries. and this study is based on secondary analysis of these datasets and hence no additional ethical clearance was sought.

Received: 5 February 2016 Accepted: 22 July 2016

Published online: 30 July 2016

\section{References}

1. World Health Organization. World Health Statistics 2012. Geneva.

2. Case A, Paxson C. Sex differences in morbidity and mortality. Demography. 2005:42:189-214.

3. Crimmins EM, Kim JK, Sole-Auro A. Gender differences in health: results from SHARE, ELSA and HRS. Eur J Public Health. 2011;21:81-91.

4. World Health Organization. Life expectancy. Data by WHO regions 2013. Available from http://apps.who.int/gho/data/view.main.690?lang=en Accessed 15 Jan 2016.

5. Oksuzyan A, Juel K, Vaupel J, Christensen K. Men: good health and high mortality. Sex differences in health and aging. Aging Clin Exp Res. 2008:20:91-102.

6. Seeman TE, Merkin SS, Crimmins EM, Karlamangla AS. Disability among older Americans: national health and nutrition examination surveys 1988-94 and 199-2004. A.JPH. 2010;100:100-7.

7. Malmusi D, Artazcoz L, Benach J, Borrell C. Perception or real illness? How chronic conditions contribute to gender inequalities in self-rated health. Eur J Public Health. 2012;22(6):781-6.

8. Moussavi S, Chatterij S, Verdes E, Tandon A, Patel V, Ustun B. Depression, chronic diseases, and decrements in health: results from the World Health Surveys. Lancet. 2007:370:851-8.

9. Hosseinpoor AR, Stewart Williams J, Amin A, Araujo de Carvalho I, Beard J, et al. Social determinants of self-reported health in women and Men: understanding the role of gender in population health. PLoS One. 2012:7(4):e34799. doi:10.1371/journal.pone.0034799.

10. Kaleta D, Makowiec-Dabrowska T, Jegier A. Employment status and selfrated health. Int J Occup Med Env Health. 2008;21:227-36.

11. Verbrugge LM. The twain meet: empirical explanations of sex differences in health and mortality. J Health Soc Behav. 1989;30:282-304.

12. Hibbard JH, Pope CR. Gender roles, illness orientation and use of medical services. Soc Sci Med. 1983;17:129-37.

13. Macintyre S, Hunt K, Sweeting H. Gender differences in health: are things really as simple as they seem? Soc Sci Med. 1996;42:617-24.

14. Ware Jr JE. The status of health assessment 1994. Ann Rev Public Health. 1995;16:327-54

15. McHorney CA. Health status assessment methods for adults: past accomplishments and future challenges. Ann Rev Public Health. 1999;20:309-35.

16. Stucki G, Kostanjsek N, Ustün B, Cieza A. ICF-based classification and measurement of functioning. Eur J Phys Rehabil Med. 2008;44:315-28.

17. Wilson M, Allen DD, Corser LJ. Improving measurement in health education and health behaviour research using item response modelling. Health Educ Res. 2006;21:i4-i18.

18. DeSalvo KB, Bloser N, Reynolds K, He J, Muntner P. Mortality prediction with a single general self-rated health question. J Gen Intern Med. 2006;21:267-75. 
19. Idler EL, Benyamini Y. Self-rated health and mortality: A review of twentyseven community studies. J Health Soc Behav. 2007;38:21-37.

20. Herdman M, Gudex C, Lloyd A, Janssen MF, Kind P, Parkin D, et al. Development and preliminary testing of the new five-level version of EQ-5D (EQ-5D-5L). Qual Life Res. 2011;20:1727-36.

21. Pickard AS, Kohlmann T, Janssen MF, Bonsel G, Rosenbloom S, Cella D. Evaluating equivalency between response systems: application of the Rasch model to a 3-level and 5-level EQ-5D. Med Care. 2007:45:812-9.

22. Rose GA. The diagnosis of ischaemic heart pain and intermittent claudication in field surveys. Bull World Health Organ. 1962;27:645-58.

23. Cook DG, Shaper AG, Macfarlane PW. Using the WHO (Rose) angina questionnaire in cardiovascular epidemiology. Int J Epidemiol. 1989;18:607-13.

24. Veenhof C, Bijlsma JW, van den Ende CH, van Dijk GM, Pisters MF, Dekker J. Psychometric evaluation of osteoarthritis questionnaires: a systematic review of the literature. Arthritis Rheum. 2006:55:480-92.

25. Pekkanen J, Pearce N. Defining asthma in epidemiological studies. Eur Respir J. 1999;14:951-7.

26. Torén K, Brisman J, Järvholm B. Asthma and asthma-like symptoms in adults assessed by questionnaires. Chest. 1993;104:600-8.

27. Kessler RC, Ustun B. The world mental health survey initiative version of the world health organization (WHO) composite international diagnostic interview (CIDI). Int J Methods Psychiatric Res. 2004;13:93-121.

28. Greenland S, Robins JM. Conceptual problems in the definition and interpretation of attributable fractions. Am J Epidemiol. 1998;128(6):1185-97.

29. Gaye A, Klugman J, Kovacevic M, Twigg S, Zambrano E. Measuring key dispararities in human development: the gender inequality index. UNDP Human Development Research Paper 2010/46. New York. December 2010

30. Orfila F, Ferrer M, Lamarca R, et al. Gender differences in health-related quality of life among the elderly: the role of objective functional capacity and chronic conditions. Soc Sci Med. 2006;63:2367-80.

31. Arber S, Cooper H. Gender differences in health in later life: the new paradox? Soc Sci Med. 1999;48:61-76.

32. World Health Organization. The ICD-10 Classification of Mental and Behavioural Disorders. Diagnostic and Research Criteria. 1993. http://www.who.int/classifications/icd/en/GRNBOOK.pdf

33. Fakhoury M. New insights into the neurobiological mechanisms of major depressive disorders. Gen Hosp Psychiatry. 2015:37:172-7.

34. World Health Organization Multicountry Survey Data Archive. World Health Surveys. Available at http://apps.who.int/healthinfo/systems/surveydata/ index.php/catalog/whs/about.. Accessed 14 Apr 2016.

35. Kowal P, Chatterji S, Naidoo N, Biritwum R, Fan W, Lopez Ridaura R, et al. Data resource profile: the world health organization study on global AGEing and adult health (SAGE). Int J Epidemiol. 2012;41:1639-49.

36. Salomon J, Tandon A, Murray CJL. Comparability of self rated health: cross sectional multi country survey using anchoring vignettes. BMJ. 2004;328:258

\section{Submit your next manuscript to BioMed Central and we will help you at every step:}

- We accept pre-submission inquiries

- Our selector tool helps you to find the most relevant journal

- We provide round the clock customer support

- Convenient online submission

- Thorough peer review

- Inclusion in PubMed and all major indexing services

- Maximum visibility for your research

Submit your manuscript at www.biomedcentral.com/submit

) Biomed Central 